\title{
Efficacy and safety of Sahastara remedy for pain relief: A systematic review and meta-analysis of randomized controlled trials
}

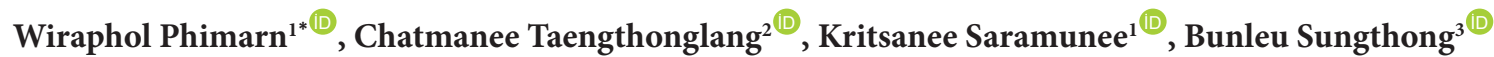 \\ ${ }^{1}$ Social Pharmacy Research Unit, Faculty of Pharmacy, Mahasarakham University, Kantharawichai, Maha Sarakham, Thailand, 44150 \\ ${ }^{2}$ Pharmacy Department, Surin Hospital, Surin, Thailand, 32000 \\ ${ }^{3}$ Pharmaceutical Chemistry and Natural Products Research Unit, Faculty of Pharmacy, Mahasarakham University, Kantharawichai, Maha Sarakham, \\ Thailand, 44150
}

\section{A R T I C L E I N F O}

Article Type:

Review

\section{Article History:}

Received: 15 June 2021

Accepted: 28 July 2021

\section{Keywords:}

Analgesic

Adverse effect

Efficacy

Pain relief

\begin{abstract}
A B S T R A C T
The Sahastara (SHT) remedy is an herbal medicine that can be used as an alternative treatment for improving pain symptoms. The aim of this study was to evaluate the efficacy and safety of the SHT remedy for pain relief. PubMed, Scopus, ScienceDirect, TCI, and ThaiLis were systematically searched for relevant articles from inception to April 2021. We only included randomized clinical trials (RCTs) in which the efficacy and safety of the SHT remedy were compared with those of non-steroidal anti-inflammatory drugs (NSAIDs). Study selection, data extraction, and quality assessment were independently performed by two reviewers. The clinical therapeutic outcomes were the pain score, WOMAC score, Oswestry Disability Index score, 100 meters walk result, global assessment, and adverse events of the SHT remedy. The outcomes were assessed and pooled using a random-effects model. Heterogeneity was assessed using the $\mathrm{I}^{2}$ test. Four studies with 213 participants were included in the analysis. The efficacy of the SHT remedy was not different from that of NSAIDs in terms of the pain score (standardized mean difference $[\mathrm{SMD}]=-0.31 ; 95 \% \mathrm{CI}=-1.26,0.65 ; \mathrm{I}^{2}=91 \%$ ), WOMAC score $\left(\mathrm{SMD}=0.05 ; 95 \% \mathrm{CI}=-0.30,0.41 ; \mathrm{I}^{2}=0.0 \%\right)$, Oswestry Disability Index score $(\mathrm{SMD}=-0.41$, $95 \% \mathrm{CI}=-1.18,0.35), 100$ meters walk result $\left(\mathrm{SMD}=0.31 ; 95 \% \mathrm{CI}=-0.25,0.87 ; \mathrm{I}^{2}=0.0 \%\right)$, and global assessment (relative risk $=0.85 ; 95 \% \mathrm{CI}=0.62,1.16 ; \mathrm{I}^{2}=0.0 \%$ ). Moreover, there were no statistically significant differences between the SHT remedy and NSAID treatment groups in terms of adverse events or liver function. This meta-analysis demonstrated that the SHT remedy is not different from NSAIDs in terms of clinical therapeutic efficacy and adverse events. However, larger and well-designed studies are needed to confirm this conclusion.
\end{abstract}

Implication for health policy/practice/research/medical education:

This meta-analysis might be useful for introducing the Sahastara remedy as an alternative for pain management.

Please cite this paper as: Phimarn W, Taengthonglang C, Saramunee K, Sungthong B. Efficacy and safety of Sahastara remedy for pain relief: A systematic review and meta-analysis of randomized controlled trials. J Herbmed Pharmacol. 2021;10(4):375-382. doi: 10.34172/jhp.2021.44.

\section{Introduction}

Pain is a common symptom and an important clinical complaint. The proportion of adults who report pain complaints is approximately $30.7 \%$ annually. Approximately 9-12 million people in the US suffer from chronic pain (1). Oral and topical non-steroidal antiinflammatory drugs (NSAIDs) are commonly used to relieve pain. However, the gastrointestinal side effects of traditional NSAIDs have been well documented (2).
The cardiovascular adverse events (AEs) of specific cyclooxygenase-2 (COX-2) inhibitors have been reported as well (3). Currently, alternative medicines are most frequently used to treat pain (4). Based on several previous findings, it appears that alternative therapies can serve as effective adjunctive treatments for chronic pain (1).

Sahastara (SHT) is a traditional Thai medicine remedy. This remedy contains 21 medicinal plants, which include Piper nigrum Linn., Plumbago indica 
Linn., Piper retrofractum, Kleinhovia hospita Linn., Baliospermum montanum Muell A., Acorus calamus Linn., Cinnamomum camphora Linn., Myristica fragrans Houtt., Lepidium sativum Linn., Myristica fragrans Houtt., Anethum graveolens Linn., Ferula asafoetida Linn., Pimpinella anisum Linn., Cuminum cyminum Linn., Merremia vitifolia (Burm. f.) Hallier f., Nigella sativa Linn., Anacyclus pyrethrum (L.) DC, Atractylodes lancea (Thunb) DC., Picrorhiza kurroa Benth., and Terminalia chebula Retz. The main ingredients are Piper nigrum, Piper retrofractum, and Plumbago indica. The Thai National List of Essential Medicine (Thai NLEM) states that the SHT remedy is indicated for pain management in musculoskeletal disease (5). The possible mechanism of the SHT remedy is the inhibition of nitric oxide (NO) and COX-2 $(6,7)$. Therefore, this remedy is likely to be as effective as NSAIDs.

In a previous clinical study, the SHT remedy combined with Thai massage was compared with Thai massage alone in patients with muscle pain. The results showed that the SHT-treated group had significantly reduced pain scores (8) and that there was no difference in pain reduction between the two groups. The study by Suakitiikul et al (9) illustrated that SHT cream reduced knee pain score without any serious side effects. Nootim et al (10) conducted a clinical trial and compared the efficacy of the SHT remedy and NSAIDs in participants with muscle pain. The results showed that SHT capsule was not different from ibuprofen in terms of pain relief in patients with acute low back pain.

Regardless of the findings of these studies, there is currently no systematic review (SR) and meta-analysis (MA) on the efficacy and safety of the SHT remedy for pain relief in comparison to those of NSAIDs. Therefore, the aim of this systematic review and meta-analysis was to examine the efficacy of the SHT remedy for pain reduction in musculoskeletal disease.

\section{Methods}

Reports of randomized controlled trials (RCTs) in which oral SHT was compared with oral NSAIDs for pain management were identified by searching PubMed, Scopus, ScienceDirect, TCI, and ThaiLis. Following terms were used for the search: Sahastara, pain, non-steroidal anti-inflammatory drugs, and NSAIDs. A historical search of the reference lists of relevant studies and narrative reviews was conducted. Unpublished data were not included in the present study.

\section{Selection criteria}

The inclusion criteria for the SR and MA were as follows: (1) RCTs in which the efficacy of oral SHT for pain management was compared with that of NSAIDs and (2) studies published in English or Thai. Studies that did not report on the therapeutic outcomes relevant to the present study were excluded from the analysis.
Data collection and analysis

All abstracts and published full reports identified as potentially relevant during the literature search were assessed for inclusion in the review. For studies that met the inclusion criteria, the following data were collected using a standard form: primary author's name, year and source of publication, country of origin, study design, treatment allocation, blinding, outcome measurement, patient's baseline, sex, age, dosage regimen, and AEs. The methodological qualities of eligible studies were independently assessed by two assessors (WP and CT). The qualities of the RCTs were assessed using the scale developed by Jadad et al. (11). The scale had a maximum score of five points, focusing exclusively on three dimensions of internal validity, namely: randomization, blinding, and patient attrition. Studies with a score of two points or less were considered low-quality studies, whereas those with three or more points were of high quality.

The studies included in this review were independently assessed for the risk of bias (ROB) by researchers (WP, CT) using the Cochrane ROB tool for RCTs. The Cochrane ROB tool has several domains, which include sequence generation, allocation concealment, blinding of participants and personnel, blinding of outcome assessment, incomplete outcome data, selective reporting, and other sources of bias. The overall ROB in each study was classified as low risk (low ROB in all key domains), high risk (high ROB in one or more key domains), or unclear risk (unclear ROB in one or more key domains without high ROB in any domain) (12). Any discrepancies in the assessment were discussed thoroughly with a third author (BS).

\section{Statistical analysis}

The primary outcomes of this study were pain score, Western Ontario and McMaster Universities Osteoarthritis Index (WOMAC) score, Oswestry Disability Index score, 100 meters walk result, and global assessment, whereas the secondary outcome was AEs. The efficacies of the treatments for the improvement of the pain score, WOMAC score, Oswestry Disability Index score, and 100 meters walk result were estimated using standardized mean difference (SMD) with 95\% confidence interval (CI). Global assessment and AEs were pooled using relative risk $(\mathrm{RR})$ together with $95 \% \mathrm{CI}$. The $\mathrm{I}^{2}$ statistic was used to define statistical heterogeneity among studies at a significance level of $\mathrm{I}^{2}>50 \%$ (13). Regarding the global assessment of osteoarthritis (OA) treatment, we classified the participants into two groups as follows: none-moderate better was classified as good, and very much better-excellent was classified as excellent.

Dersimonian and Laird's random-effects model was used for the analysis of all outcomes. Publication bias was assessed using a funnel plot. Egger's regression test was used to detect funnel plot asymmetry $(14,15)$. Statistical analysis was performed using RevMan version 5.3 and 
STATA version 14 . The significance level was set at $P<$ 0.05 .

This MA confirmed the robustness of the results. A fixed-effects model was used to analyze the sensitivity test results.

\section{Results}

Study characteristics

The details of the literature search and selection process are summarized in Figure 1. Six potentially relevant articles were identified after the screening of titles and abstracts through the systematic literature search. The identified articles were then selected for a full-text review. Two articles were excluded because one of them was a report of a phase I clinical trial, whereas the other was a comparative study of the SHT remedy and massage. Therefore, four RCTs were eligible for analysis and were included in the SR and MA $(6,7,10,16)$.

The characteristics and details of the included studies are shown in Table 1 . The four studies $(6,7,10,16)$ were conducted in Thailand and included 213 participants. The SHT remedy was administered in the oral form in all the studies. Two of the trials were double-blinded RCTs. The Nootim et al study (10) was conducted to compare the efficacy of the SHT remedy with that of diclofenac $75 \mathrm{mg} / \mathrm{d}$ in participants with muscle pain. The study of Pinsornsak et al (6) was a clinical trial conducted to investigate the efficacy of SHT among patients with OA of the knee, whereas the Verayachankul et al study was performed to assess patients with acute low back pain. Katatum et al (7) conducted their study to compare the efficacy of a 1000 mg SHT capsule administered orally three times/day with diclofenac $25 \mathrm{mg}$ administered three times/day for 28 days in patients with OA. The average age of the participants in these studies was approximately $47.32 \pm 5.94$ years. The duration of the studies ranged from 7 to 28 days.

In all the included trials, the SHT remedy used was a powdered drug in a capsule, administered in doses ranging from $1200-4050 \mathrm{mg} / \mathrm{d}$. However, only two studies $(6,7)$ reported the markers of SHT remedy. The piperine is a majority marker of the SHT remedy.

Assessment of methodological quality and ROB

All the studies were judged to have high methodological quality. Three studies $(6,7,10)$ were rated $5 / 5$, whereas one study was rated $3 / 5$ on the Jadad scale because it was a single-blinded RCT that did not report on allocation concealment or blinding between groups (Table 1). The details of the ROB assessment are shown in Figure 2. Only one trial was found to have high $\mathrm{ROB}$ in random sequence generation, allocation concealment, and blinding of participants, personnel, and outcome evaluators.

Primary outcomes

Pain score

The aggregated results showed no significant difference in the pain score between the SHT remedy group and NSAID group $(\mathrm{SMD}=-0.31 ; 95 \% \mathrm{CI}=-1.26,0.65 ; P<0.00001)$

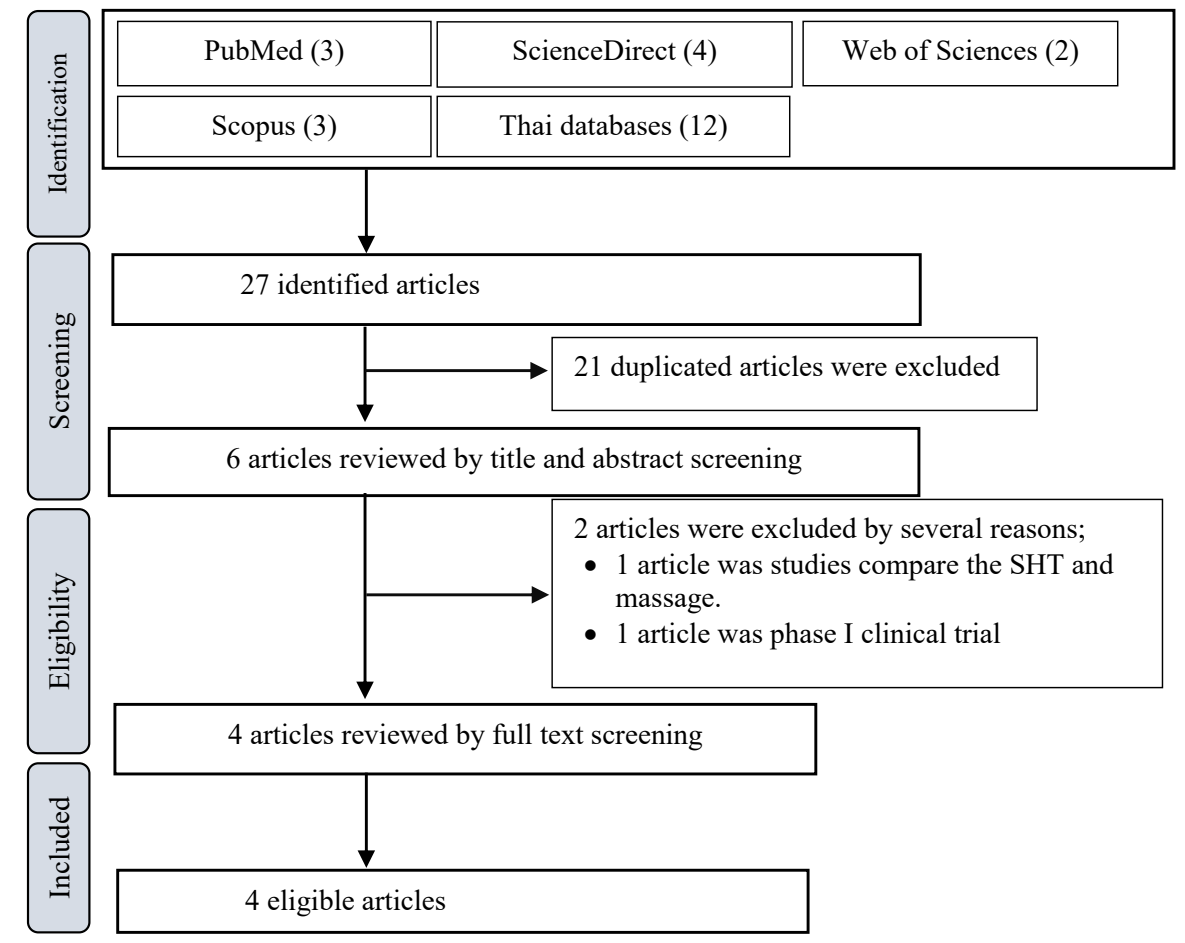

Figure 1. A PRISMA flow diagram describing the selection process for identifying included studies. 
Table 1. Characteristics of the included studies

\begin{tabular}{|c|c|c|c|c|c|c|c|c|}
\hline Authors & Design & Participants & Intervention (n) & NSAIDs (n) & Duration & Outcomes & Results & $\begin{array}{l}\text { Jadad } \\
\text { score }\end{array}$ \\
\hline $\begin{array}{l}\text { Nootim et al } \\
\text { (10) }\end{array}$ & DRCT & Muscle pain & $\begin{array}{l}\text { The SHT capsule } \\
400 \mathrm{mg} \text { tid }(n=31)\end{array}$ & $\begin{array}{l}\text { Diclofenac } 25 \\
\text { mg tid }(n=31)\end{array}$ & 7 days & Pain score & $\begin{array}{l}\text { The SHT and } \\
\text { diclofenac reduced } \\
\text { pain score } \\
\text { significantly }(P<0.05)\end{array}$ & 5 \\
\hline $\begin{array}{l}\text { Pinsornsaket } \\
\text { al (6) }\end{array}$ & DRCT & $\begin{array}{l}\text { OA of the } \\
\text { knee }\end{array}$ & $\begin{array}{l}\text { The SHT extract } \\
\text { capsule } 1000 \mathrm{mg} \\
\text { tid ( } \mathrm{n}=31 \text { ) } \\
\text { (piperine not less } \\
\text { than } 19 \mathrm{mg} / \mathrm{g} \text { of } \\
\text { extract) }\end{array}$ & $\begin{array}{l}\text { Diclofenac } 25 \\
\text { mg tid }(n=30)\end{array}$ & 28 days & $\begin{array}{l}\text { VAS, WOMAC index } \\
\text { score, } 100 \text {-meter walk } \\
\text { time test, ADR, renal } \\
\text { and liver function test }\end{array}$ & $\begin{array}{l}\text { There were no } \\
\text { differences between } \\
\text { the SHT and } \\
\text { diclofenac in all } \\
\text { outcomes }\end{array}$ & 5 \\
\hline $\begin{array}{l}\text { Verayachankul } \\
\text { et al (16) }\end{array}$ & $\mathrm{RCT}$ & $\begin{array}{l}\text { Acute low } \\
\text { back pain }\end{array}$ & $\begin{array}{l}\text { The SHT capsule } \\
1350 \mathrm{mg} \text { tid }(n=14)\end{array}$ & $\begin{array}{l}\text { Ibuprofen } 400 \\
\text { mg tid }(n=13)\end{array}$ & 7 days & $\begin{array}{l}\text { Pain score, Oswestry } \\
\text { disability index score, } \\
\text { ADR }\end{array}$ & $\begin{array}{l}\text { There were } \\
\text { no differences } \\
\text { between the SHT } \\
\text { and ibuprofen in all } \\
\text { outcomes }\end{array}$ & 3 \\
\hline $\begin{array}{l}\text { Kakatum et } \\
\text { al (7) }\end{array}$ & DRCT & $\begin{array}{l}\text { OA of the } \\
\text { knee }\end{array}$ & $\begin{array}{l}\text { The SHT extract } \\
\text { capsule } 1000 \mathrm{mg} \\
\text { tid ( } \mathrm{n}=32 \text { ) (piperine } \\
\text { not less than } 19 \\
\mathrm{mg} / \mathrm{g} \text { of extract) }\end{array}$ & $\begin{array}{l}\text { Diclofenac } 25 \\
\text { mg tid }(n=31)\end{array}$ & 28 days & $\begin{array}{l}\text { VAS, WOMAC index } \\
\text { score, } 100 \text {-meter walk } \\
\text { time test, ADR, renal } \\
\text { and liver function test }\end{array}$ & $\begin{array}{l}\text { SHT capsules relieve } \\
\text { inflammation } \\
\text { symptom on OA } \\
\text { patients as effectively } \\
\text { as diclofenac }\end{array}$ & 5 \\
\hline
\end{tabular}

Abbrevations: RCT, randomized controlled trial; DRCT, double-blind randomized controlled trial; OA, Osteoarthritis; SHT, Sahastara; tid, three times per day; VAS, visual analog scale; WOMAC, the Western Ontario and McMaster Universities Arthritis Index; ADR, adverse drug reaction.

(Figure 3). Heterogeneity was observed in the case of this outcome $\left(\mathrm{I}^{2}=91 \%\right)$.

\section{WOMAC score}

The WOMAC score was reported in only two studies $(6,7)$, whereas the Oswestry Disability Index score was reported in one study (16). There was no significant difference between these two outcomes $(\mathrm{SMD}=0.05 ; 95 \%$ $\mathrm{CI}=-0.30,0.41 ; \mathrm{I}^{2}=0.0 \%$ and $\mathrm{SMD}=-0.41 ; 95 \% \mathrm{CI}=$ $-1.18,0.35 ; \mathrm{I}^{2}=\mathrm{N} / \mathrm{A}$, respectively) (Figure 4).

\section{0 meters walk}

The mean \pm SD of the 100 meters walk results was reported in two RCTs $(6,7)$. The MA indicated that SHT treatment had no statistically significant effect on this outcome compared to NSAIDs $(\mathrm{SMD}=0.31 ; 95 \% \mathrm{CI}=-0.25,0.87$; $P=0.28)$. These results showed heterogeneity $\left(\mathrm{I}^{2}=60.0 \%\right.$, $P=0.11$ ) (Figure 5).

\section{Global assessment}

Global assessment was reported in two RCTs $(6,7)$. The number of participants in the SHT group who showed much better and excellent improvement in symptom scores was not statistically significant compared with that in the NSAID group $(\mathrm{RR}=0.85 ; 95 \% \mathrm{CI}=0.62,1.16$; $P=0.30)$. No heterogeneity was observed in this outcome $\left(\mathrm{I}^{2}=0.0 \%, P=0.64\right)$ (Figure 6$)$.

Secondary outcomes

AEs were reported in two trials. The most commonly reported adverse drug reactions were abdominal pain, constipation, and dry mouth and throat. The pooled results of the RR of AEs in the SHT remedy group compared with those of the NSAID group are shown in Table 2. There were no significant differences between the two groups.

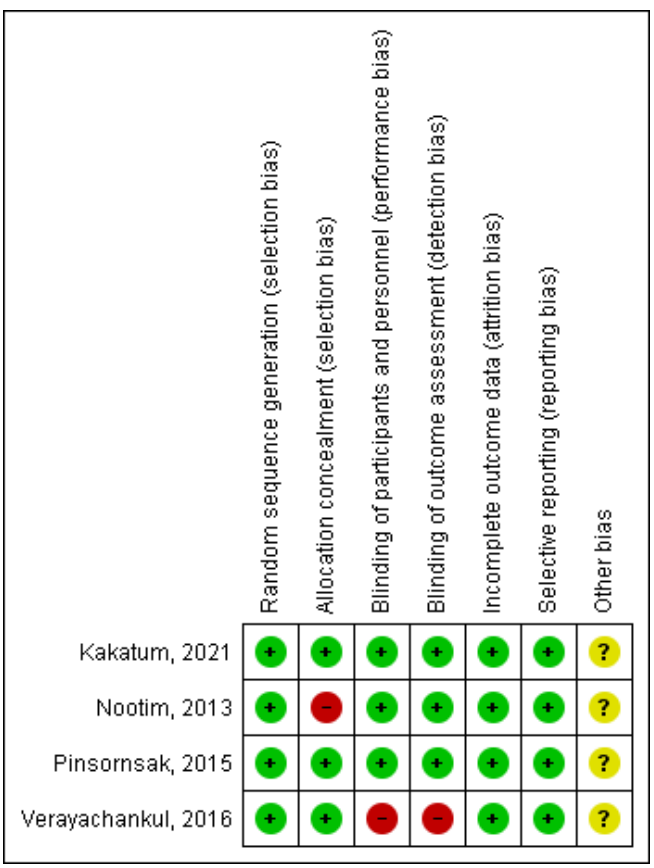

Figure 2. Methodological quality assessment of the included studies based on the Cochrane Handbook. 


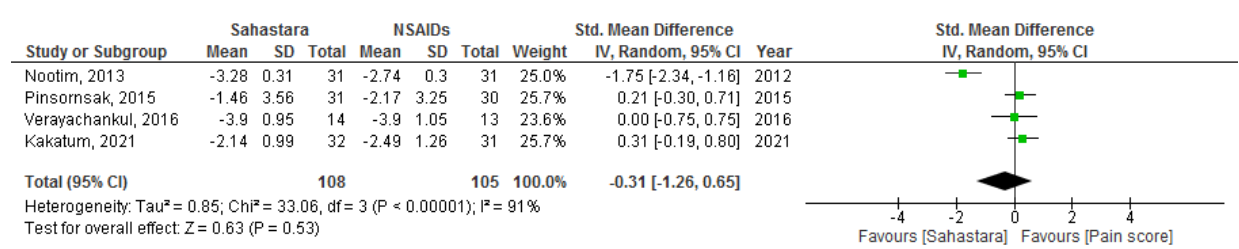

Figure 3. The effect of SHT remedy on pain score.

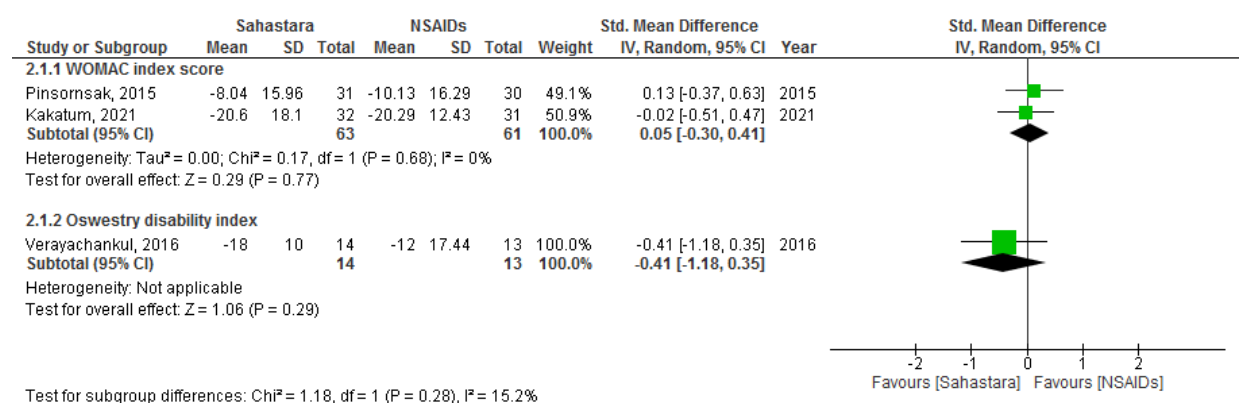

Figure 4. The effect of SHT remedy on WOMAC score and Oswestry disability index score.

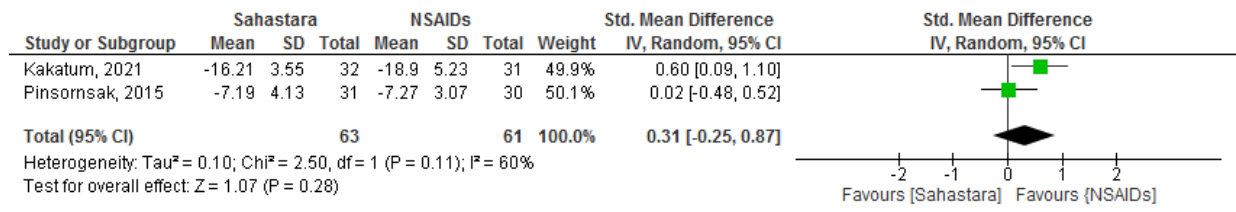

Figure 5. The effect of SHT remedy on 100 meters walk.

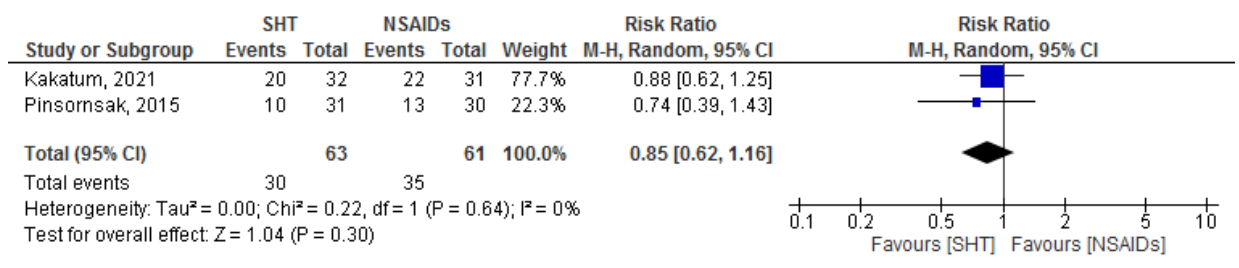

Figure 6. The effect of SHT remedy on the global assessment.

\section{Liver function test}

The effects of the SHT remedy on renal and liver functions were reported in two trials $(6,7)$, which included 124 participants. The results of the MA showed that the liver function test result of the SHT remedy group was not different from that of the NSAID group (aspartate transaminase [AST] level: SMD $=-0.16 \mathrm{U} / \mathrm{L} ; 95 \% \mathrm{CI}=$ $-0.52,0.19 ; \mathrm{I}^{2}=0.0 \%$ and alanine transaminase $[\mathrm{ALT}]$ : $\left.\mathrm{SMD}=-0.46 \mathrm{U} / \mathrm{L} ; 95 \% \mathrm{CI}=-0.82,-0.11 ; \mathrm{I}^{2}=0.0 \%\right)$.

Sensitivity analysis

The results of the sensitivity analysis are presented in Table 3. In this analysis, the model was changed to a fixedeffects model. The main results of the clinical efficacy of the SHT remedy did not change (Table 3).
Publication bias

The publication bias in the clinical therapeutic efficacy of the SHT from three studies was analyzed. The funnel plot was nearly symmetrical. These results indicated no potential publication bias (Figure 7).

\section{Discussion}

This study is the first systematic review and meta-analysis in which the efficacy and safety of the SHT remedy for pain management were measured. Our study illustrated that the SHT remedy, when used as monotherapy, is as effective as an NSAID for pain management. In addition, the remedy produced few adverse effects. However, these positive findings should be interpreted cautiously because of the small sample size in each study included in this MA. 
Table 2. Adverse events of the Sahastara (SHT) remedy vs non-steroidal anti-inflammatory drugs (NSAIDs)

\begin{tabular}{|c|c|c|c|c|c|}
\hline Adverse events (No of reference) & No of AE in SHT group & No of AE in NSAIDs group & Pooled RR (95\% Cl) & $I^{2}(\%)$ & $P$ value ${ }^{a}$ \\
\hline Abdominal pain (3) & $24 / 77$ & $14 / 77$ & $1.42(0.19,10.61)$ & $74.0 \%$ & 0.02 \\
\hline Constipation (3) & $4 / 77$ & $2 / 74$ & $1.70(0.36,7.96)$ & $0.0 \%$ & 0.87 \\
\hline Dry mouth and throat (3) & $5 / 77$ & $4 / 74$ & $1.23(0.34,4.38)$ & $0.0 \%$ & 0.58 \\
\hline Sweating (2) & $2 / 63$ & $3 / 61$ & $0.65(0.11,3.85)$ & $0.0 \%$ & 0.71 \\
\hline Dizziness (2) & $2 / 63$ & $3 / 61$ & $0.65(0.11,3.85)$ & $0.0 \%$ & 0.71 \\
\hline Diarrhea (1) & $1 / / 14$ & $0 / 13$ & $2.80(0.12,63.20)$ & N/A & N/A \\
\hline Nausea (1) & $1 / 14$ & $1 / 13$ & $0.93(0.06,13.37)$ & N/A & N/A \\
\hline Thirst (1) & $0 / 14$ & $2 / 13$ & $0.19(0.01,3.56)$ & N/A & N/A \\
\hline Headache (1) & $2 / 14$ & $1 / 13$ & $1.86(0.19,18.13)$ & N/A & N/A \\
\hline Tiredness (1) & $2 / 14$ & $1 / 13$ & $1.86(0.19,18.13)$ & N/A & $\mathrm{N} / \mathrm{A}$ \\
\hline Hot flashes (1) & $2 / 14$ & $0 / 13$ & $4.67(0.24,88.96)$ & N/A & N/A \\
\hline
\end{tabular}

Abbreviations: RR, risk ratio; NA, not applicable; AEs, adverse events.

a $P$ value for heterogeneity.

Table 3. Sensitivity analysis outcomes compared with main analysis

\begin{tabular}{lll}
\hline Outcomes & Main analysis & Sensitivity analysis \\
\hline Pain score & $\mathrm{SMD}=-0.31 ; 95 \% \mathrm{Cl}:-1.26,0.65 ; \mathrm{I}^{2}=91 \%$ & $\mathrm{SMD}=-0.23 ; 95 \% \mathrm{Cl}:-0.52,0.05 ; \mathrm{I}^{2}=91 \%$ \\
WOMAC score & $\mathrm{SMD}=0.05 ; 95 \% \mathrm{Cl}:-0.30,0.41 ; \mathrm{I}^{2}=0.0 \%$ & $\mathrm{SMD}=0.05 ; 95 \% \mathrm{Cl}:-0.30,0.41 ; \mathrm{I}^{2}=0.0 \%$ \\
Oswestry disability index score & $\mathrm{SMD}=-0.41 ; 95 \% \mathrm{Cl}:-1.18,0.35 ; \mathrm{I}^{2}=\mathrm{N} / \mathrm{A}$ & $\mathrm{SMD}=-0.41 ; 95 \% \mathrm{Cl}:-1.18,0.35 ; \mathrm{I}^{2}=\mathrm{N} / \mathrm{A}$ \\
$\begin{array}{l}100 \text { meters walk } \\
\text { Global assessment }\end{array}$ & $\mathrm{SMD}=0.31 ; 95 \% \mathrm{Cl}:-0.25,0.87 ; \mathrm{I}^{2}=60.0 \% \quad \mathrm{SMD}=0.31 ; 95 \% \mathrm{Cl}:-0.05,0.66 ; \mathrm{I}^{2}=60.0 \%$ \\
\hline
\end{tabular}

Abbreviations: SMD, standardized mean difference; RR, risk ratio; NA, not applicable.

The SHT remedy was included as an herbal medicine on the Thai NLEM 2019. Current evidence supports the mechanism of action of the SHT remedy for pain relief. The SHT remedy exerts inhibitory effects on NO production and the release of tumor necrosis factor-alpha (TNF- $\alpha$ ) and prostaglandin E2 (PGE2) (7). SHT extract capsules with piperine as the main component (not less than $19 \mathrm{mg} / \mathrm{g}$ of extract) were used in only two studies (6, 7 ) included in the present study. The anti-inflammatory effects of piperine have been reported, previously (17).

Ying et al (18) reported that piperine exerts antiinflammatory effects on human OA chondrocytes by inhibiting interleukin (IL)- $1 \beta$, which induces the production of PGE2 and NO. Regarding the possible mechanism for pain relief, piperine reportedly desensitizes the transient receptor potential vanilloid subfamily 1 (TRPV1) receptor, mostly expressed in the C- and $\mathrm{A} \delta$ fibers of primary sensory neurons (19). Furthermore, other compounds in the SHT remedy, camphor and asafoetida, are reported to strongly inhibit transient receptor potential ankyrin 1 (TRPA1) channels, which have a role in peripheral pain sensation $(20,21)$.

Regarding safety, the results of this MA showed that the SHT remedy is safe for short-term use. These results are consistent with those of Kanokkangsadal et al (22), who investigated the clinical safety of capsules of ethanolic extracts of the SHT remedy, administered in doses of 300 and $600 \mathrm{mg} / \mathrm{d}$, in healthy volunteers for 28 days. No serious AEs were reported in either group in the aforementioned study; laboratory results showed no clinically significant differences between the groups as well. There was no significant difference between both SHT doses, especially in terms of the effects on liver and renal functions, including AST, ALT, alkaline phosphatase (ALP), and creatinine levels. The SHT remedy extract capsules did not have toxic effects on liver and renal functions. This finding is similar to that of a report on toxicity in rats administered with a single oral dose of 5000 $\mathrm{mg} / \mathrm{kg}$ body weight of SHT extract and rats administered with oral doses of 10,100 , and $1000 \mathrm{mg} / \mathrm{kg}$ body weight of SHT extract daily for 270 days. The rats did not show significant acute and chronic toxicity (23).

The results of the present MA showed that abdominal pain, which was reported in three of the included studies, was the most common adverse drug reaction among these studies $(6,7,16)$. This finding is not surprising because the SHT remedy contains spicy medicinal plants, such as the Piper species (pepper and long pepper). However, the major constituent is piperine, which may induce gastrointestinal side effects (6).

The primary strength of the present study was its systematic approach. Indeed, this is the first SR and MA in which the efficacy and safety of the SHT remedy for pain management were compared with those of NSAIDs. 


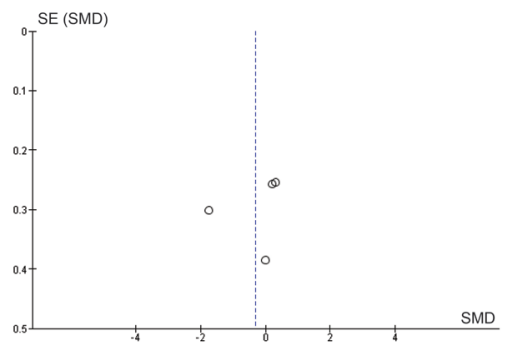

Pain score

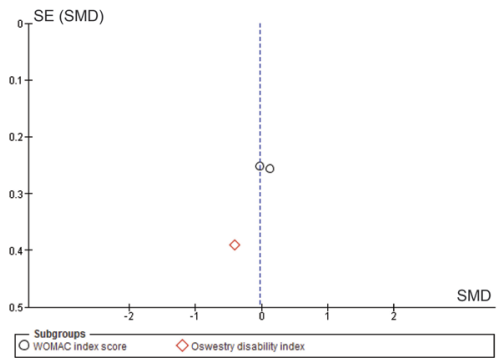

WOMAC score and Oswestry disability index score

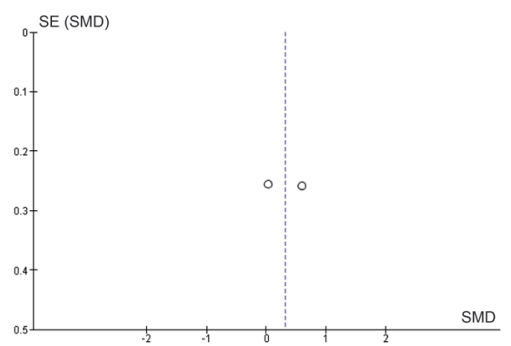

100 meter walk

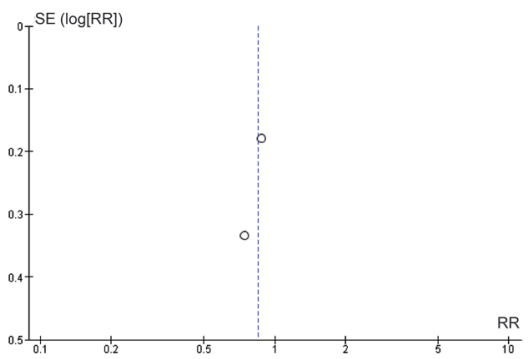

Global assessment

Figure 7. Publication bias.

All the included studies were rated as high-quality studies. However, one of the major limitations of this study is the possible existence of bias due to the small-study effects of most of the included RCTs. In addition, we found that the SHT remedy was safe when used for 28 days. Therefore, the long-term effects and safety of the SHT remedy need be investigated.

\section{Conclusion}

Based on current evidence, the SHT remedy when used as monotherapy is as effective as an NSAID for pain relief in musculoskeletal disease. No serious AEs were reported in the studies included in this MA. However, further welldesigned, large, multicenter RCTs investigating the longterm effects of the SHT remedy are needed to support the current evidence.

\section{Authors' contributions}

WP, CT, BS reviewed and contributed to data collection and preparation of the manuscript. The first draft was prepared by WP, CT, KS. All authors read the final version and confirmed it for publication.

\section{Conflict of interest}

The authors declare that they have no conflict of interest.

\section{Ethical considerations}

Ethical issues (including plagiarism, data fabrication, double publication etc) have been completely observed by the authors. Ethical consideration was not required. We performed the protocol in accordance with PRISMA guideline.

\section{Funding/Support}

This research project was financially supported by Mahasarakham University (Grant No. 2564).

\section{References}

1. Urits I, Schwartz RH, Orhurhu V, Maganty NV, Reilly BT, Patel PM, et al. A comprehensive review of alternative therapies for the management of chronic pain patients: acupuncture, Tai Chi, osteopathic manipulative medicine, and chiropractic care. Adv Ther. 2021;38(1):76-89. doi: 10.1007/s12325-02001554-0.

2. Labianca R, Sarzi-Puttini P, Zuccaro SM, Cherubino P, Vellucci R, Fornasari D. Adverse effects associated with non-opioid and opioid treatment in patients with chronic pain. Clin Drug Investig. 2012;32 Suppl 1:53-63. doi: 10.2165/11630080-000000000-00000.

3. Patrono C, Baigent C. Nonsteroidal anti-inflammatory drugs and the heart. Circulation. 2014;129(8):907-16. doi:10.1161/circulationaha.113.004480.

4. Simpson CA. Complementary medicine in chronic pain treatment. Phys Med Rehabil Clin N Am. 2015;26(2):321-47. doi: 10.1016/j.pmr.2014.12.005.

5. Thai National Drug Committee. National list of essential medicines A.D. 2019 (List of herbal medicinal products). Bangkok: Chumnum sahakorn karnkaset of Thailand Press Ltd; 2019.

6. Pinsornsak P, Kanokkangsadal P, Itharat A. The clinical efficacy and safety of the Sahastara remedy versus diclofenac in the treatment of osteoarthritis of the knee: a double-blind, randomized, and controlled trial. Evid Based Complement Alternat Med. 
2015;2015:103046. doi: 10.1155/2015/103046.

7. Kakatum N, Pinsornsak P, Kanokkangsadal P, Ooraikul B, Itharat A. Efficacy and safety of Sahastara remedy extract capsule in primary knee osteoarthritis: a randomized double-blinded active-controlled trial. Evid Based Complement Alternat Med. 2021;2021:6635148. doi: 10.1155/2021/6635148.

8. Singtong $\mathrm{P}$, Soonyarach W, Phaikhomnam P. Effectiveness of traditional Thai massage with Sahasthara drug used for treatment of shoulder muscle pain. J Tradit Thai Med Res. 2016;2(2):13-24.

9. Suakitiikul T, Pongcharoen B, Itharat A, Ruangnoo S, Kanokkangsadal P, Lertdamrongdej T. Effectiveness and safety of Sahastara extract cream for knee pain in patients with primary osteoarthritis: a pilot study. Thai J Pharm Pract. 2020;12(4):1219-27.

10. Nootim P, Bunchuailua W, Kapol N. Comparative efficacy of Sahasthara capsule VS diclofenac tablet for the relief of muscle pain. J Thai Tradit Altern Med. 2013;11(1):54-65.

11. Jadad AR, Moore RA, Carroll D, Jenkinson C, Reynolds DJ, Gavaghan DJ, et al. Assessing the quality of reports of randomized clinical trials: is blinding necessary? Control Clin Trials. 1996;17(1):1-12. doi: 10.1016/0197-2456(95)00134-4.

12. Higgins JP, Altman DG, Gøtzsche PC, Jüni P, Moher $\mathrm{D}$, Oxman AD, et al. The Cochrane Collaboration's tool for assessing risk of bias in randomised trials. BMJ. 2011;343:d5928. doi: 10.1136/bmj.d5928.

13. Higgins JP, Thompson SG, Deeks JJ, Altman DG. Measuring inconsistency in meta-analyses. BMJ. 2003;327(7414):557-60. doi: 10.1136/ bmj.327.7414.557.

14. Egger M, Davey Smith G, Schneider M, Minder C. Bias in meta-analysis detected by a simple, graphical test. BMJ. 1997;315(7109):629-34. doi: 10.1136/ bmj.315.7109.629.

15. Peters JL, Sutton AJ, Jones DR, Abrams KR, Rushton L. Comparison of two methods to detect publication bias in meta-analysis. JAMA. 2006;295(6):676-80. doi: $10.1001 /$ jama.295.6.676.

16. Verayachankul $\mathrm{T}, \quad$ Chatsiricharoenkul $\mathrm{S}$, Harnphadungkit K, Jutasompakorn P, Tantiwongse J, Piwtong M, et al. Single-blind randomized controlled trial of poly-herbal formula Sahatsatara for acute low back pain: a pilot study. Siriraj Med J. 2016;68(1):306.

17. Meghwal M, Goswami TK. Piper nigrum and piperine: an update. Phytother Res. 2013;27(8):112130. doi: 10.1002/ptr.4972.

18. Ying X, Chen X, Cheng S, Shen Y, Peng L, Xu HZ. Piperine inhibits IL- $\beta$ induced expression of inflammatory mediators in human osteoarthritis chondrocyte. Int Immunopharmacol. 2013;17(2):2939. doi: 10.1016/j.intimp.2013.06.025.

19. McNamara FN, Randall A, Gunthorpe MJ. Effects of piperine, the pungent component of black pepper, at the human vanilloid receptor (TRPV1). Br J Pharmacol. 2005;144(6):781-90. doi: 10.1038/ sj.bjp.0706040.

20. Takaishi M, Uchida K, Fujita F, Tominaga M. Inhibitory effects of monoterpenes on human TRPA1 and the structural basis of their activity. J Physiol Sci. 2014;64(1):47-57. doi: 10.1007/s12576-013-0289-0.

21. Xu H, Blair NT, Clapham DE. Camphor activates and strongly desensitizes the transient receptor potential vanilloid subtype 1 channel in a vanilloid-independent mechanism. J Neurosci. 2005;25(39):8924-37. doi: 10.1523/jneurosci.2574-05.2005.

22. Kanokkunsadal P, Wanichsetakul P, Itharat A. The clinical safety of Sahastara remedy ethanolic extract capsules in healthy volunteers. J Med Assoc Thai. 2018;101(10):1429-36.

23. Sireeratawong S. Acute and Chronic Toxicity of Sahastara Recipe Extract. Pathum Thani, Thailand: Faculty of Medicine, Thammasat University; 2014. 